\title{
SOSIALISASI JURNAL KEWIRAUSAHAAN DAN BISNIS UNTUK MENINGKATKAN PUBLIKASI PERGURUAN TINGGI
}

\author{
Susantiningrum¹), Eddy Triharyanto2), Dimar Hantari3) \\ 1) Fakultas Keguruan dan Ilmu Pendidikan Universitas Sebelas Maret, Jl. Ir. Sutami No.36A \\ Kentingan, Jebres, Surakarata, 57126, Indonesia \\ 2) Fakultas Pertanian Universitas Sebelas Maret, Jl. Ir. Sutami No.36A Kentingan, Jebres, \\ Surakarata, 57126, Indonesia \\ 3) Mahasiswa Program Pascasarjana S-2 Agronomi, Universitas Sebelas Maret, Jl. Ir. Sutami \\ No.36A Kentingan, Jebres, Surakarata, 57126, Indonesia \\ 1,2,3) Pusat Pengembangan Kewirausahaan LPPM Universitas Sebelas Maret, Jl. Ir. Sutami \\ No.36A Kentingan, Jebres, Surakarata, 57126, Indonesia \\ Email: susantiningrum@gmail.com
}

\begin{abstract}
ABSTRAK
Jurnal Kewiruasahaan dan Bisnis (JKB) merupakan jurnal yang diterbitkan oleh PPKwu dua kali dalam satu tahun. Saat ini jurnal telah memiliki ISSN cetak dan ISSN elektronik. Untuk masuk ke tahap jurnal yang terakreditasi, salah satu saratnya adalah artikel yang dimuat minimal terdiri dari 2 institusi yang berbeda. Mulai tahun 2015, JKB telah menerbitkan jurnal yang berisikan artikel-artikel dari dua institusi yang berbeda. Akan tetapi, artikel dari institusi selain UNS ini jumlahnya masih sedikit. Hal ini dikarenakan belum adanya sosialisasi Jurnal Kewirausahaan dan Bisnis kepada institusi lain. Kegiatan ini bertujuan untuk mensosialisasikan Jurnal Kewirausahaan dan Bisnis kepada institusi lain. Diharapkan akan meningkatkan jumlah publikasi artikel dari UNS dan institusi lain, meningkatkan jumlah peer reviewer JKB, meningkatkan branding index PPKwu, meningkatkan jaringan kerjasama sehingga dapat mencapai misi UNS yaitu UNS menuju world class university.
\end{abstract}

Kata kunci: akreditasi, bisnis, kewirausahaan

\begin{abstract}
Jurnal Kewiruasahaan dan Bisnis (JKB) is a journal published by PPKwu twice in a year. Currently the journal has a printed ISSN and an electronic ISSN. To enter the accredited journal stage, one of the provisions is that the articles published must consist of at least 2 different institutions. Starting in 2015, JKB has published a journal containing articles from two different institutions. However, there are still few articles from institutions other than the UNS. This is due to the absence of socialization of the Entrepreneurship and Business Journal to other institutions. This activity aims to socialize the Entrepreneurship and Business Journal to other institutions. Hoped that it will increase the number of article publications from UNS and other institutions, increase the number of peer reviewers of JKB, increase the branding index of PPKwu,
\end{abstract}


improve the network of collaboration so that they can achieve the UNS mission, it is UNS towards world class university.

Key words: accreditation, business, entrepreneurship

\section{PENDAHULUAN}

Pusat

pengembangan

kewirausahaan (PPKwu) merupakan salah satu pusat dibawah lembaga penelitian dan pengabdian kepada masyarakat (LPPM) Universitas Sebelas Maret (UNS yang bergerak dalam bidang pengembangan kewirausahaan dan bisnis bagi civitas akademika dan masyarakat. Saat ini PPKwu berupaya menjadi pusat mandiri yang professional yang bergerak di bidang kewirausahaan. Bentuk profesionalitas yang dapat dilakukan adalah menerbitkan jurnal di bidang kewirausahaan. Jurnal Kewirausahaan dan Bisnis ini telah terbit mulai tahun 2007 dan pada tahun 2008 telah memiliki ISSN cetak. Sedangkan versi elektronik telah diterbitkan mulai tahun 2015 dan pada awal tahun 2017 e-ISSN sudah terbit. Jurnal elektronik ini menjadi salah satu bagaian dari Open Journal System (OJS) Jurnal Universitas Sebelas Maret.

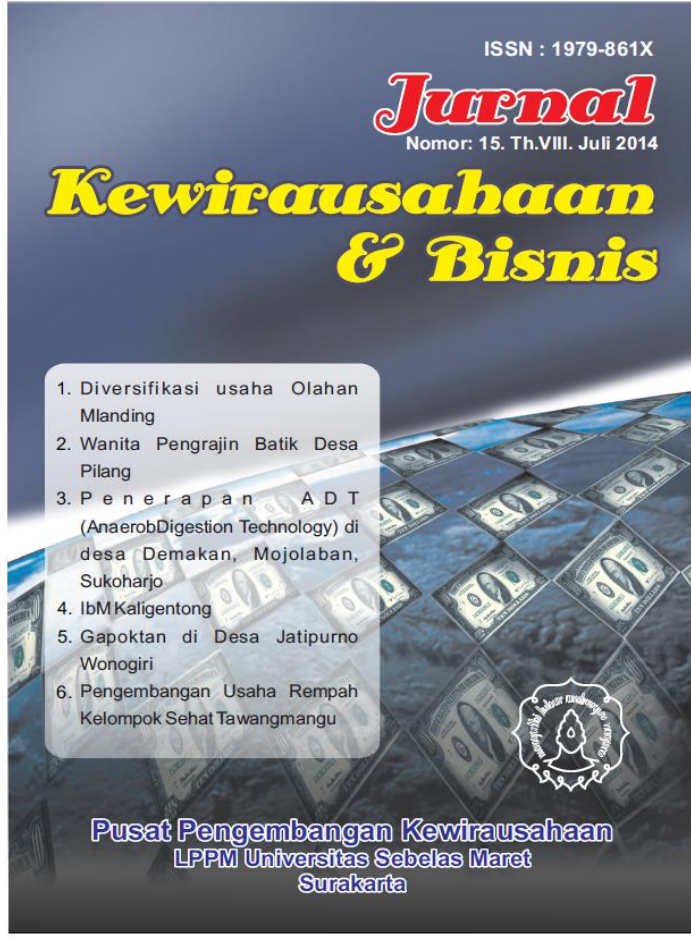

Gambar 1. Tampilan Jurnal Cetak Kewirausahaan dan Bisnis

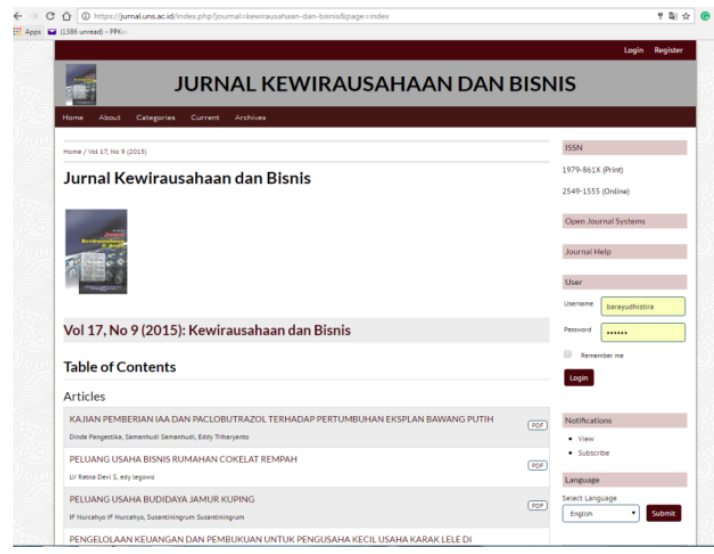

Gambar 2. Tampilan Jurnal Elektronik Kewirausahaan dan Bisnis

Saat ini, total jurnal yang terakreditasi oleh Dikti tidak lebih dari 10\% (Nashihuddin dan Aulianto, 2016). Untuk menuju ke tahapan jurnal terakreditasi, PPKwu memerlukan artikel-artikel yang 
berasal dari institusi selain UNS. Dalam satu kali terbitan minimal ada 2 institusi didalamnya. Mulai tahun 2015, PPKwu telah mulai menerbitkan artikel-artikel dengan 2 institusi yang berbeda. Akan tetapi, jumlah artikel dari institusi selain UNS jumlahnya masih sedikit. Dalam satu kali terbitan hanya ada satu artikel yang berasal dari institusi lain. Hal ini dikarenakan kurangnya publikasi kepada institusi lain mengenai adanya Jurnal Kewirausahaan dan Bisnis (JKB). Oleh karena itu, dipandang perlu untuk melakukan sosialisasi Jurnal Kewirausahaan dan Bisnis agar mendatangkan artikelartikel yang berasal dari institusi diluar UNS dan meningkatkan branding UNS, khususnya PPKwu.

\section{METODE}

Kegiatan peningkatan tata kelola di PPKwuini dibagi menjadi tiga tahapan yaitu :

1. Workshop Perbaikan Panduan Penulisan Artikel

Workshop dilakukan selama satu hari untuk memperoleh ide dan saran dari peer group dan staf PPKwu mengenai konten panduan. Workshop dilaksanakan di daerah Surakarta. Dari hasil workshop maka dapat teridentifikasi item-item yang diperlu ditambahkan atau dikurangi untuk mempermudah penulisan artikel.

\section{Workshop Panduan Mitra Bestari}

Workshop dilakukan didaerah Surakarta dengan menghadirkan seluruh Peergroup dan staff PPKwu guna mendapat ide dan saran. Workshop dilakukan selama 2 hari. Dari hasil workshop ini maka didapatkan tempat-tempat/ tujuan/ institusi untuk sosialisasi jurnal.

\section{Sosialisasi Jurnal Kewirausahaan dan Bisnis di Indonesia}

Sosialisasi jurnal dilakukan dengan membuat pamflet dan mencetak jurnal terbitan terbaru dan dikirimkan ke institusi-institusi di Indonesia.

\section{HASIL DAN PEMBAHASAN}

\section{A. Workshop Penyusunan Panduan Penulisan Artikel}

Workshop panduan penulisan artikel dilakukan pada tanggal 18-19 April 2017. Workshop ini dihadiri oleh 20 orang yang terdiri dari Peer Group, Pengelola Jurnal, Reviewer Jurnal dan Staff Administrasi PPKwu.

Workshop ini bertujuan untuk merevisi panduan penulisan artikel yang telah ada agar lebih baik lagi. Bagian-bagian yang di revisi antara lain:

1. Judul ditulis dengan huruf capital 12 pt.

2. Email yang dicantumkan hanya email penulis pertama.

3. Penulisan abstrak menjadi dalam 2 bahasa (inggris dan Indonesia) yang sebelumnya hanya dalam bahasa Indonesia saja.

4. Bab-bab dalam jurnal terdiri dari
a. Pendahuluan
b. Metode
c. Hasil dan Pembahasan
d. Kesimpulan
e. Daftar Pustaka

5. Daftar pustaka yang dicantumkan minimal 3 yang berasal dari jurnal internasional, 
jurnal nasional, buku ajar dan buku teks.

6. Penulisan jurnal harus dalam font Book Antiqua dan satu spasi.

\section{B. Workshop Penyusunan Panduan Peer Review}

Workshop ini dilakukan pada tanggal 30-31 April 2017. Kegiatan workshop kali ini dihadiri oleh 15 orang peserta yang merupakan Peer Group. Hasil dari workshop ini antara lain:

1. Membuat formulir untuk reviewer sebagai panduan untuk melakukan review Jurnal Kewirausahaan dan Bisnis. Adapun formulir tersebut terdiri dari:

a. Kelengkapan dan kesesuaian format jurnal.

b. Kualitas dari tulisan.

c. Komentar mengenai isi jurnal mulai dari pendahuluan, metode, hasil dan pembahasan, kesimpulan dan daftar pustaka.

\section{Penggandaan dan Pengiriman Jurnal}

Penggandaan Jurnal dilakukan secara bertahap, penggandaan pertama dilakukan pada bulan Juli dan penggandaan kedua pada bulan September. Total Jurnal yang digandakan sebanyak 100 eksemplar. 40 jurnal disosialisasikan melalui kegiatan PPKwu berupa FGD yang dilakukan di beberapa kota. Sedangkan 60 jurnal lainnya di kirimkan via pos ke instansi-instansi seluruh Indonesia. Instansi-instansi yang akan dikirimkan jurnal terlebih dahulu didiskusikan dalam kegiatan rapat penentuan instansi pengiriman jurnal.

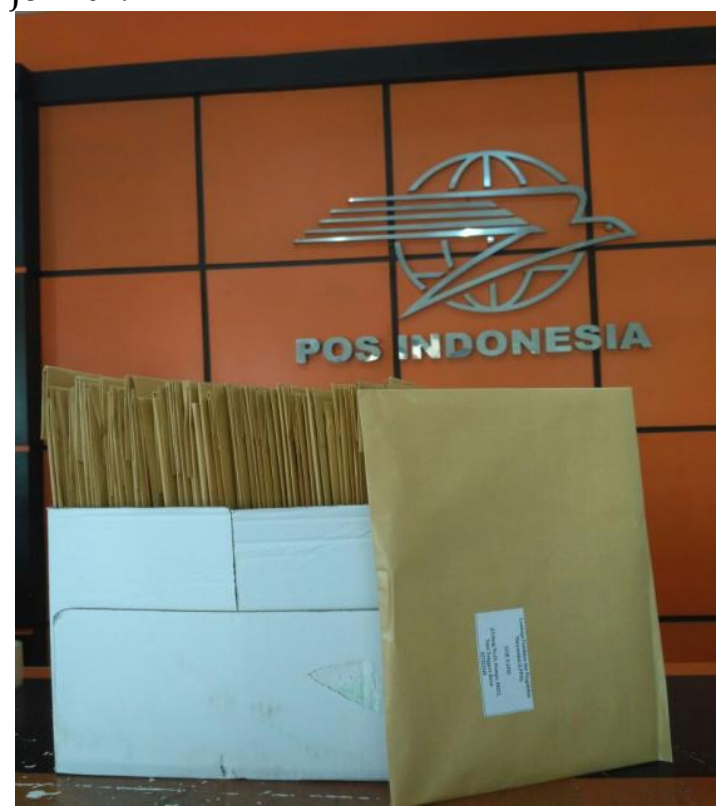

Gambar 3. Pengiriman Jurnal

\section{D.Peningkatan Jumlah Artikel Luar UNS \\ Hasil dari sosialisasi Jurnal} Kewirausahaan dan Bisnis di seluruh Indonesia, banyak artikel-artikel yang masuk di website JKB dari luar UNS. Sampai tanggal 12 Desember 2017, telah terdapat 20 jurnal luar UNS yang sudah masuk di website.

\section{KESIMPULAN}

1. Panduan penulisan artikel telah dirubah dibeberapa bagian seperti format, ketemtuan isi dan ketentuan daftar pustaka.

2. Penduan peer review telah dissusun melalui kegiatan workshop.

3. Jurnal Kewirausahaan dan Bisnis telah di sosialisasikan ke seluruh Indonesia. 


\section{DAFTAR PUSTAKA}

LIPI. 2014. Peraturan Kepala LIPI

Nomor 3 Tahun 2014 Tentang

Pedoman Akreditasi Terbitan

Terbitan Berkala Ilmiah. Jakarta.

Nashihuddin W, Aulianto D R. 2016.

Pengelolaan Terbitan Berkala

Ilmiah Sesuai Ketentuan

Akreditasi: Upaya Menuju

Jurnal Trakreditasi dan

Bereputasi Internasional.

Jurnal Pustakawan Indonesia, 15

(1-2): 83-98. 